\title{
AMC Integrated Multilayer Wearable Antenna for Multiband WBAN Applications
}

\author{
Iqra Aitbar ${ }^{1}$, Nosherwan Shoaib ${ }^{1, *}$, Akram Alomainy ${ }^{2}$, Abdul Quddious $^{3}$, Symeon Nikolaou $^{4}$, \\ Muhammad Ali Imran ${ }^{5}$ and Qammer H. Abbasi ${ }^{5}$
}

\author{
${ }^{1}$ Research Institute for Microwave and Millimeter-Wave Studies (RIMMS) National University of Sciences and \\ Technology (NUST), H-12 44000, Islamabad, Pakistan \\ ${ }^{2}$ School of Electronic Engineering and Computer Science, Queen Mary University of London, London, E1 4NS, UK \\ ${ }^{3}$ KIOS Research and Innovation Center of Excellence, University of Cyprus, 2109, Nicosia, Cyprus \\ ${ }^{4}$ Frederick Research Center (FRC) and Department of Electrical Engineering, Frederick University, 1036, Nicosia, Cyprus \\ ${ }^{5}$ James Watt School of Engineering, University of Glasgow, Glasgow, G12 8QQ, U.K \\ *Corresponding Author: Nosherwan Shoaib. Email: nosherwan.shoaib@rimms.nust.edu.pk \\ Received: 25 August 2021; Accepted: 12 October 2021
}

\begin{abstract}
In this paper, a compact, efficient and easy to fabricate wearable antenna integrated with Artificial Magnetic Conductor (AMC) is presented. Addition of slots and bevels/cuts in the rectangular monopole patch antenna yield a wide bandwidth along with band notches. The proposed antenna is backed with an AMC metasurface that changes the bidirectional radiation pattern to a unidirectional, thus, considerably reducing the Specific Absorption Ratio (SAR). The demonstrated antenna has a good coverage radiating away from the body and presents reduced radiation towards the body with a front-to-back ratio of $13 \mathrm{~dB}$ and maximum gain of $3.54 \mathrm{~dB}$. The proposed design operates over a wide frequency band of 2.9 to $12 \mathrm{GHz}$ (exceeding the designated 3.1-10.6 GHz Ultra-Wideband (UWB) band). The band notches were created using slots on the radiating patch in the sub-bands from 5.50 to $5.67 \mathrm{GHz}$ and 7.16 to $7.74 \mathrm{GHz}$. The overall dimensions of the structure are $33 \times 33 \times 6.75 \mathrm{~mm}^{3}$. The antenna's radiation performance increased considerably with the addition of the AMC layer. The SAR values for the antenna are reduced by $85.3 \%$ when the AMC is used and are $0.083 \mathrm{~W} / \mathrm{kg}$ which is well below the FCC SAR limits. The simple design, miniaturized profile, low SAR and wide operating bands with multiple band notches make the presented antenna an appealing choice for several UWB wearable body area network (WBAN) applications.
\end{abstract}

Keywords: Ultra-wideband (UWB); monopole antenna; wearable antenna; specific absorption ratio (SAR) 


\section{Introduction}

In February 2002, the Federal Communications Commission (FCC) has regularized the unlicensed wireless communication over the Ultra-wideband (UWB) range i.e., 3.1 to $10.6 \mathrm{GHz}$, with an Effective Isotropic Radiated Power (EIRP) level of $-41.25 \mathrm{dBm} / \mathrm{MHz}$ [1]. This wide bandwidth can be used to transmit fast pulses as opposed to the widely used narrow band radio links where continuous waves are used. The UWB systems, providing the supported high data rate and the low power consumption, are suitable for medium range UWB wearable body area network (WBAN) networks [2], including military, medical and entertainment applications. Inevitably, the UWB systems have to overcome potential interference with applications that share the same spectrum, for example, the 3.3 to $3.7 \mathrm{GHz}$ WLAN IEEE $802.11 \mathrm{a}$, the 5.15 to $5.825 \mathrm{GHz}$ HIPERLAN/2 band, 7.25 to $7.75 \mathrm{GHz}$ X-band satellite downlink and ITU services at 8.025 to $8.4 \mathrm{GHz}$. Therefore, the UWB antennas can be designed to have stop band characteristics at some of these frequencies. In addition, the Wearable antennas have to comply with challenging requirements related to radiations next to human body, which may cause frequency detuning due to lossy nature and high dielectric property of human tissues. These problems can be overcome through effective design techniques including the use of a metamaterial multi-layer stacking [3]. The metamaterials are artificial engineered materials which are typically constructed in the form of an array of unique unit cells. The metamaterials are often integrated with wearable antennas to enhance the desired antenna parameters and to compensate the loading effect of human body. One of the subclasses of planar metamaterials is the frequency selective surfaces (FSSs) which can be designed as a 'spatial filter' for microwave frequencies. The FSS is typically formed by 2D periodic elements array which provide spatial filtering. The conducting parts of the array act as band stop filter whereas slots act as band pass filters. FSS could improve the performance of antenna in terms of gain and the directivity, it is thus preferred in wearable electronics as it could safeguard the human skin underneath. Frequency selective surface can use the ultra-wide stopband by way of reflectors for UWB antennas [4].

The FSSs can be further categorized into artificial magnetic conductor (AMC) or high impedance surface (HIS) [5]. AMCs' are a subset of FSS which are periodic arrays, generally in a complimentary manner offering a wide range of applications and antenna enhancements. The AMCs mimic the behavior of perfect magnetic conductors (PMC) by producing in phase zero-degree reflections at resonant frequencies and are thus, quite useful for planar miniature antenna enhancements. The reflection phase of AMC's can be tuned to produce reconfigurable mechanism in antennas, such as frequency and beam steering by tunable AMC. The AMCs are designed as metallic patterns on a dielectric substrate to resonate at a particular band. The geometry of these metallic unit cells determine the specifications of the antenna, including the SAR level and the efficiency.

The wearable antennas are placed close to the body, therefore, their potential safety in terms of SAR should meet the limitations defined by the US (FCC) or Europe (CISPR). An efficient way to reduce the SAR level is by incorporating the AMC, which is a promising technique with low cost and easy implementation and can reduce the SAR level up to 64\% [5], while maintaining or even increasing the gain and bandwidth. The AMC has an inherent feature of resonance; therefore, its bandwidth needs to be improved for wide band operations. The 3D structure multilayered AMC antennas have substantiated in reducing SAR and increasing the gain [6]. Similarly, in [7], a reflector backed multilayered AMC antenna has been proposed to change bidirectional radiation pattern to unidirectional. The said design has shown better results than planar metal surface antennas in terms of front to back ratio and the efficiency. 
As mentioned before, the UWB systems are purposely designed to eliminate certain frequency bands. For this purpose, several techniques are put forth such as use of matching network with frequency selective properties, design of antenna with inherent low pass filter properties and use of multilayered resonant structures. The use of matching network for frequency selective characteristics increases the complexity, cost and size of the antenna, which are undesirable for UWB systems. To keep the system compact, the antennas with inherent notch filters or multilayered structures are used, which can be realized by incorporating the slots or radiating patch [8]. Other methods include using different geometric shapes for radiating structures such as L-shaped [9], inverted C-shaped [10], spiral parasitic elements [11] and bouquet like shape [12].

In this paper, a compact monopole patch antenna integrated with AMC layer is presented the antenna exhibits high gain, covering UWB with band notches to avoid interference and the low SAR level. The square and triangular bevels/cuts and slots are introduced in antenna's radiating patch to achieve the entire UWB range with necessary band notches. The antenna is layered with AMC at the bottom to change the omni-directional radiation pattern into unidirectional, thus reducing SAR level along with detuning effects and increase gain. The outline of the paper is structured in five sections. Section 2 presents the proposed structure i.e., a combination of UWB antenna and AMC. Section 3 discusses the design methodology that includes mathematical modelling and design steps of both layers. The results and discussions are presented in Section 4 followed by conclusion in Section 5 .

\section{Design Model}

A microstrip fed monopole antenna with an AMC reflector, operating in the UWB range, is presented here. The addition of two slots cause the notches as demonstrated in $[13,14]$. The matching of the UWB monopole is improved by beveling the corners of the radiating patch from the side of the ground plane edge. Finally, a UWB unit cell is designed, that would behave as FSS when the patterns are periodically repeated, generating a $4 \times 4$ AMC metasurface. The proposed UWB antenna is presented in Fig. 1 and the unit cell and its array are shown in Fig. 2. The optimized design dimensions are summarized in Tab. 1.

\section{Design Methodology}

\subsection{UWB Antenna Design}

The proposed rectangular microstrip monopole antenna consists of radiating patch, feed line, the metallic ground and the substrate, as shown in Fig. 1. The half-cut ground differentiates monopole antenna from other patch antennas.

The mathematical model of this patch is derived using transmission line model presented in [15]. The equations for width and length can be written as follows:

$$
\begin{aligned}
& W=\frac{v_{0}}{2 f_{r}} \sqrt{\frac{2}{\varepsilon_{r}+1}} \\
& L=\frac{v_{0}}{2 f_{r} \sqrt{\varepsilon_{r e f f}}}-2 \Delta L
\end{aligned}
$$

where, $\mathrm{f}_{\mathrm{r}}$ is operating frequency, $\varepsilon_{\mathrm{r}}$ is the dielectric of the substrate, $v_{0}$ is the speed of light, $\varepsilon_{\text {reff }}$ is the effective dielectric constant and $\Delta L$ is the extension in length of the substrate. $\varepsilon_{\text {reff }}$ and $\Delta L$ are calculated as follows: 


$$
\begin{aligned}
& \mathcal{E}_{\text {reff }}=\frac{\mathcal{E}_{r}+1}{2}+\frac{\mathcal{E}_{r}-1}{2}\left[1+10 \frac{h}{W}\right]^{-1 / 2} \\
& \Delta L=0.412 h \frac{\left(\mathcal{E}_{\text {reff }}+0.3\right)\left(\frac{W}{h}+0.264\right)}{\left(\mathcal{E}_{\text {reff }}-0.258\right)\left(\frac{W}{h}+0.8\right)}
\end{aligned}
$$

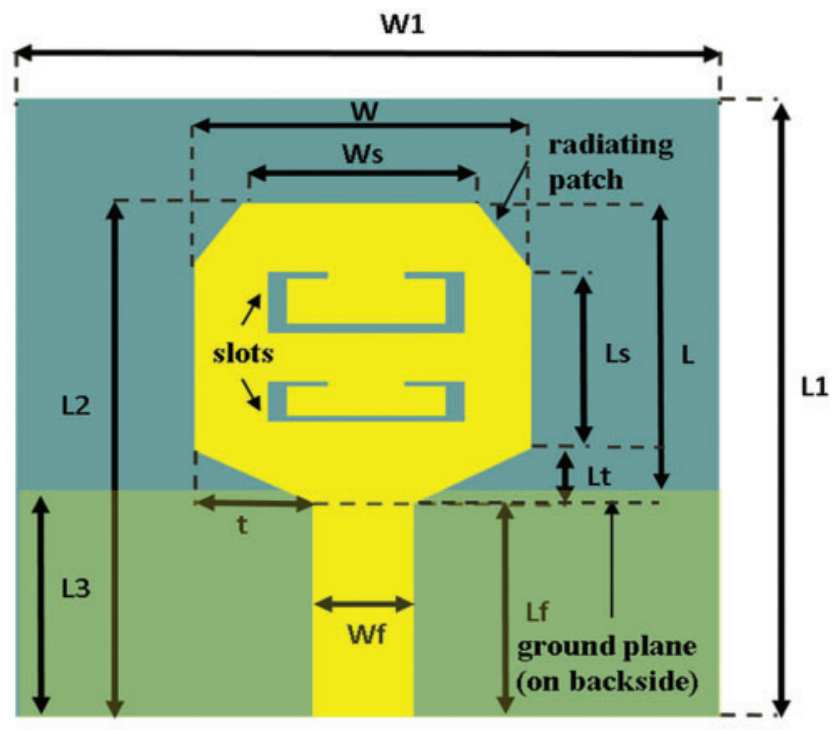

(a)
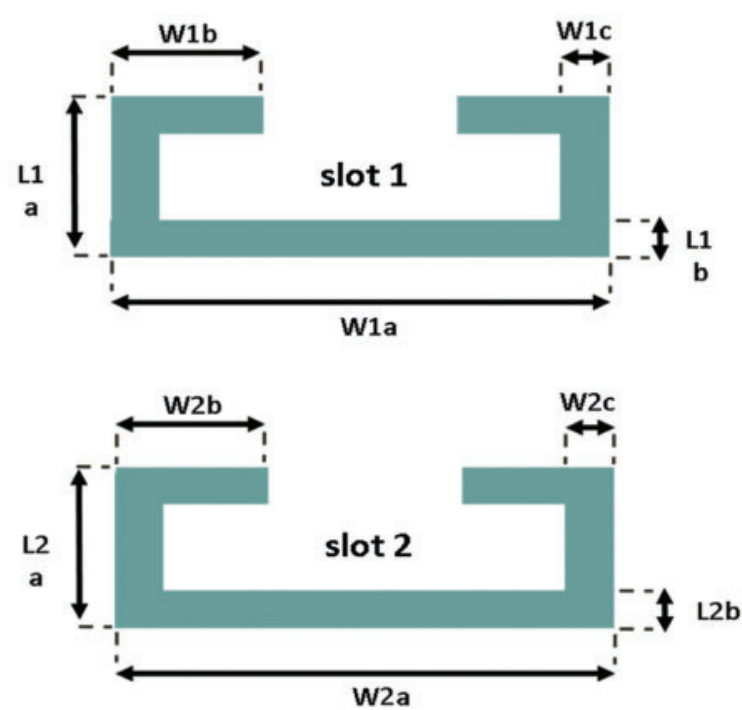

(b)

Figure 1: (a) Proposed UWB antenna with slots (b) close up view of the slots

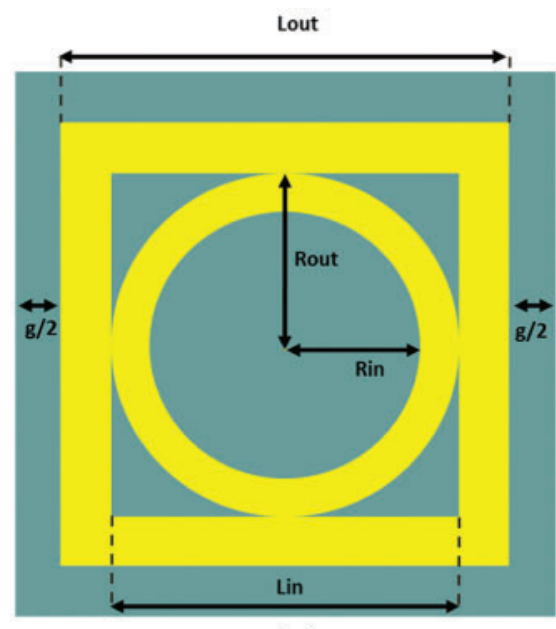

(a)

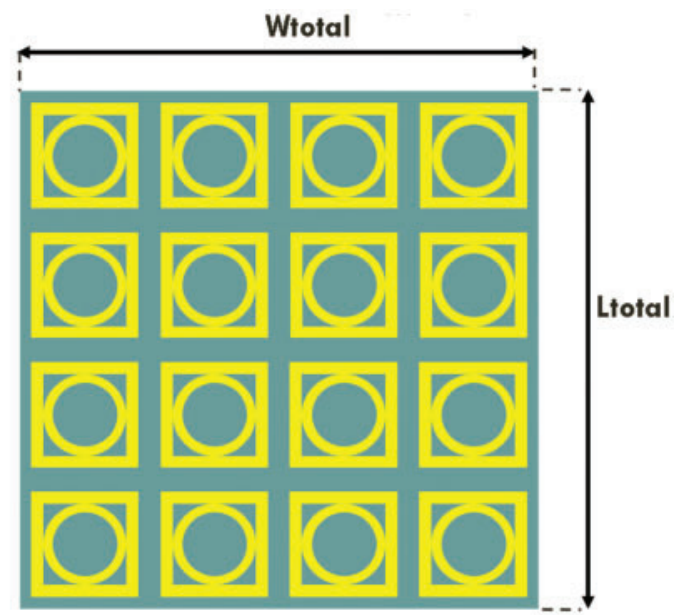

(b)

Figure 2: (a) Proposed UWB unit cell (b) $4 \times 4$ array of unit cells forming AMC

Using the FR4 substrate with $\varepsilon_{r} \cong 4.4, \mathrm{f}_{\mathrm{r}}=6.5 \mathrm{GHz}$ and $v_{0}=3 \times 10^{8}$ and $\mathrm{h}=1.6 \mathrm{~mm}, \mathrm{~W}=57.01$ $\mathrm{mm}, \mathrm{L}=44.39 \mathrm{~mm}, \mathrm{E}_{\text {reff }}=4.1705$ and $\Delta L=5.628 \mathrm{~mm}$. 
Table 1: Optimized dimensions of the proposed antenna and the AMC

\begin{tabular}{|c|c|c|c|c|c|c|c|c|}
\hline S. No & Parameter & $\begin{array}{l}\text { Dimension } \\
(\mathrm{mm})\end{array}$ & S. No & Parameter & $\begin{array}{l}\text { Dimension } \\
(\mathrm{mm})\end{array}$ & S. No & Parameter & $\begin{array}{l}\text { Dimension } \\
(\mathrm{mm})\end{array}$ \\
\hline 1 & $\mathrm{~W}_{1}$ & 28 & 11 & $\mathrm{~W}_{\text {la }}$ & 7 & 21 & $\mathrm{R}_{\text {out }}$ & 3.15 \\
\hline 2 & $\mathrm{~L}_{1}$ & 29 & 12 & $\mathrm{~L}_{1 \mathrm{a}}$ & 3.8 & 22 & $\mathrm{R}_{\text {in }}$ & 2.6 \\
\hline 3 & $\mathrm{~L}_{2}$ & 25 & 13 & $\mathrm{~L}_{1 \mathrm{~b}}$ & 0.3 & 23 & $\mathrm{~L}_{\text {out }}$ & 7 \\
\hline 4 & $\mathrm{~L}_{\mathrm{f}}$ & 11.5 & 14 & $\mathrm{~W}_{1 \mathrm{~b}}$ & 2.5 & 24 & $\mathrm{~L}_{\text {in }}$ & 5.9 \\
\hline 5 & $\mathrm{~L}_{\mathrm{s}}$ & 8.4 & 15 & $\mathrm{~W}_{1 \mathrm{a}}$ & 0.8 & 25 & $\mathrm{G}$ & 0.59 \\
\hline 6 & $\mathrm{~L}_{\mathrm{t}}$ & 1.5 & 16 & $\mathrm{~W}_{2 \mathrm{a}}$ & 7 & 26 & $\begin{array}{l}\text { Substrate } \\
\text { thickness }\end{array}$ & 1.524 \\
\hline 7 & $\mathrm{~W}_{\mathrm{f}}$ & 3 & 17 & $\mathrm{~L}_{2 \mathrm{a}}$ & 1.8 & 27 & $\mathrm{~W}_{\text {total }}$ & 33 \\
\hline 8 & $\mathrm{~W}_{\mathrm{s}}$ & 10 & 18 & $\mathrm{~L}_{2 b}$ & 0.3 & 28 & $\mathrm{~L}_{\text {total }}$ & 33 \\
\hline 9 & $\mathrm{~T}$ & 6 & 19 & $\mathrm{~W}_{2 \mathrm{~b}}$ & 2.5 & & & \\
\hline 10 & $\mathrm{~L}_{3}$ & 25 & 20 & $\mathrm{~W}_{2 \mathrm{c}}$ & 0.8 & & & \\
\hline
\end{tabular}

The design evolution steps of UWB antenna model and their respective frequency responses as presented in Fig. 3. The initial antenna parameters are obtained using the mathematical Eqs. (1)-(4) and a simple monopole patch antenna is designed. It can be seen from the frequency response of the antenna shown in Fig. 3a that it resonates between 8.25 to $10.28 \mathrm{GHz}$ and does not cover the UWB range i.e., 3.1 to $10.6 \mathrm{GHz}$. To enhance the bandwidth, the rectangular and triangular bevels/cuts were made in the top and bottom of the patch (see Fig. 3b), similar to [16], which generated a resonating frequency response over 3.865 to $11.04 \mathrm{GHz}$. In addition, the band notches are achieved through slots as shown in Fig. 3c. The band notches are achieved at 5.50 to $5.67 \mathrm{GHz}$ (i.e., IEEE 802.11 WLAN) and 7.16 to $7.74 \mathrm{GHz}$ (i.e., X-band Downlink).

\subsection{Design of the FSS}

To make the antenna suitable for wearable applications, an FSS with an array of conductive unit cells can be used as bottom layer. The FSS would resonate at a particular frequency band but will remain transparent to other, thus, creating a partially reflecting surface. The FSS, when integrated with a PEC ground plane, reflects the transmitted waves outside the resonance band. Using this configuration, the grounded FSS can improve the gain and provide an almost constant gain across the frequency of interest. The initial parameters, taken from [17], to design the square unit cell are: $W=0.12 \lambda_{0}, \quad g=0.02 \lambda_{0}, \quad h=0.04 \lambda_{0} W=0.12 \lambda_{0}, \quad g=0.02 \lambda_{0}, \quad h=0.04 \lambda_{0}$. For the case of $\mathrm{UWB}$, the $f_{0}=6.5 \mathrm{GHz}$, is the mid frequency which generates $\varepsilon_{\mathrm{r}}=4.4$ (here, $\lambda_{0}$ is the wavelength at $\left.f_{0}\right)$. The in-phase band varying between $-90^{\circ}$ and $90^{\circ}$ is controlled by the width ' $\mathrm{W}$ ' of the unit cell. The requirement for UWB unit cell substrate was a wider $\mathrm{Q}$ factor. Therefore, the FR4 substrate was chosen with a dielectric constant of 4.4 at $6.5 \mathrm{GHz}$, loss tangent of 0.045 and a thickness of $\mathrm{h}=1.54$ $\mathrm{mm}$, so to obtain a wide in-phase band. After parametric analysis, the optimized values i.e., $\mathrm{W}=7$ $\mathrm{mm}, \mathrm{g}=0.5 \mathrm{~mm}$ and $\mathrm{h}=1.54 \mathrm{~mm}$ are obtained to achieve the desired frequency band. The unit cell's initial and evolved model are shown in Figs. 2a and b, respectively. 


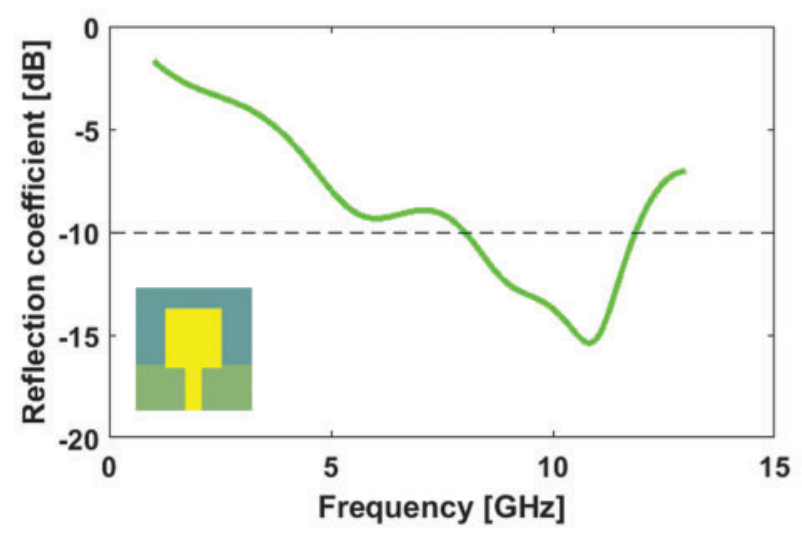

(a)

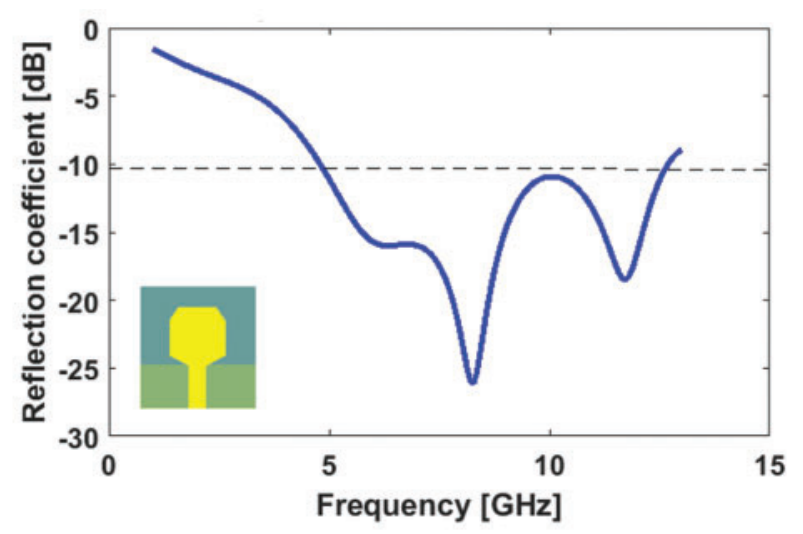

(b)

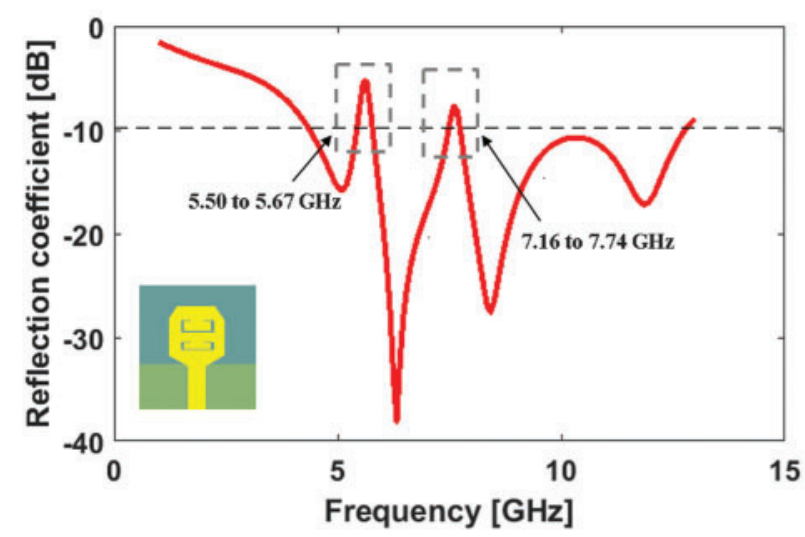

(c)

Figure 3: UWB antennas frequency response (a) design A (b) design B (c) design C

\subsection{Utilization of Square Loop and Circular Ring in FSS}

The square loop and circular ring can be utilized to achieve UWB behavior in FSS. The square loop resonates when the length of all the four sides becomes equal to quarter wavelength, while the ring resonates when its diameter is $D=\frac{\lambda}{\pi}$. The integration of both will lead to a wide band response, where the square loop controls lower cut-off frequency, while the circular ring controls the higher resonance frequency. This makes the metasurface act like an FSS. The passband between the two cutoff frequencies is dictated by the distance between square loop and circular ring as shown in Fig. 2a where the distance or gap is donated by " $\mathrm{g}$ ". The height of substrate is directly proportional to dielectric constant, so by choosing a substrate with higher dielectric constant, the unit cell can be made compact. Therefore, the FR4 was chosen as substrate for AMC.

After careful consideration and rigorous parametric sweeps, the dimensions of unit cell came out to be Rout $=3.15 \mathrm{~mm}$, Rin $=2.6 \mathrm{~mm}$, Lout $=7 \mathrm{~mm}$, Lin $=5.9 \mathrm{~mm}, \mathrm{~g}=0.59 \mathrm{~mm}$ and substrate thickness of $1.524 \mathrm{~mm}$. These dimensions can be correlated with Fig. $2 \mathrm{~b}$.

To observe the frequency and phase behavior of the unit cell, the floquet ports feature of Ansys HFSS was used. The frequency response of both initial and evolved unit cell design are shown in Figs. $4 \mathrm{a}$ and 4b, it can be seen that initial model is just a high pass filter while the evolved model acts 
as a band pass filter. The phase response of unit cell is shown in Fig. 5, where the highlighted region shows in phase band from $90^{\circ}$ to $-90^{\circ}$ at 4.9 and $9.2 \mathrm{GHz}$ respectively. In this bandwidth the AMC would act as a magnetic conductor plane for vertical incident waves.

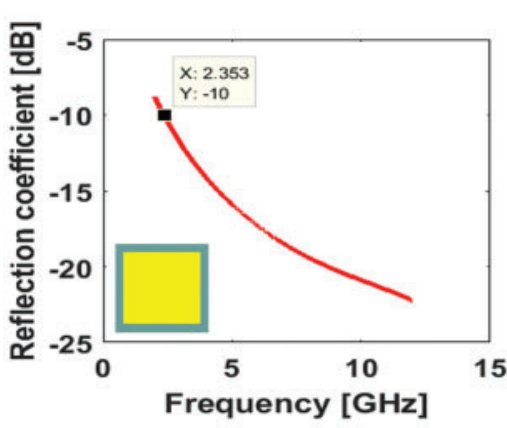

(a)

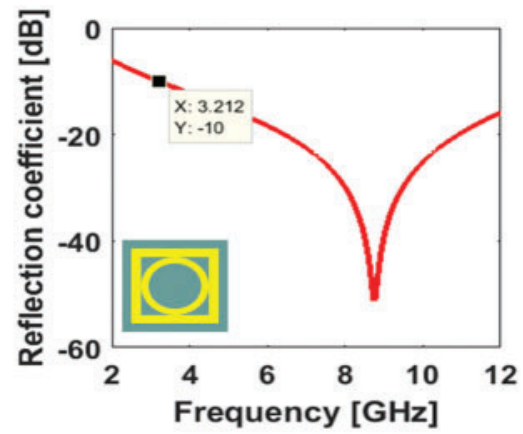

(b)

Figure 4: UWB unit cell frequency response (a) for simple rectangular patch (b) for patch with circular ring and rectangular loop

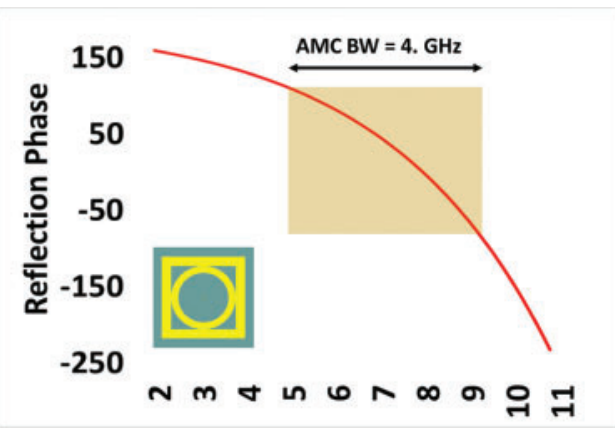

Figure 5: UWB AMC unit cell phase response

Following observations are made during design evolution of unit cell:

- The circular ring has a smaller dimension but larger cut-off frequency than square loop, therefore it can be integrated within the loop.

- The lower cut-off frequency is controlled by outer length of square loop and the gap between unit cells.

- The higher cut-off frequency of the band is controlled by internal length of square.

- The external radius of the circular ring dictates the lower cut-off frequency while the inner radius controls the upper frequency.

The unit cell in Fig. 2a was used to make a $4 \times 4$ array of metasurface backed by a ground plane with overall dimensions of $33 \mathrm{~mm} \times 33 \mathrm{~mm} \times 1.54 \mathrm{~mm}$. The AMC metasurface, shown in Fig. 2b, is layered below the antenna. 


\subsection{Equivalent Circuit Model of Unit Cell}

The UWB unit cell behaves like a resonant band pass filter in this configuration; hence its equivalent circuit model derived from [18] can be shown in Fig. 6, where capacitance $\left(C_{1}\right)$, inductance $\left(L_{1}\right)$ and Resistance $\left(R_{1}\right)$ can be written as:

$C_{1}=\frac{\varepsilon_{0} \varepsilon_{r} L W}{2 h}$

$L_{1}=\frac{1}{\omega^{2} C_{1}}$

$R_{1}=\frac{Q_{r}}{\omega C_{1}}$

$Q_{r}=\frac{v_{0} \sqrt{\mathcal{E}_{r}}}{4 f_{r} h}$

where, $\mathrm{h}$ is the height of substrate. For FR4 substrate with $\varepsilon_{\mathrm{r}} \cong 4.4, \mathrm{f}_{\mathrm{r}}=6.5 \mathrm{GHz}$ and $v_{0}=3 \times 10^{8}$ and $\mathrm{h}=1.6 \mathrm{~mm}$ and dimensions of unit cell $\mathrm{L}=\mathrm{W}=7.59 \mathrm{~mm}$. The calculated values from above set of equations come out as: $\mathrm{C}_{1}=92.3 \mathrm{nF}, \mathrm{L}_{1}=6.67 \mathrm{fF}, \mathrm{Q}_{\mathrm{r}}=15.1, \mathrm{R}_{1}=6.68 \Omega$.

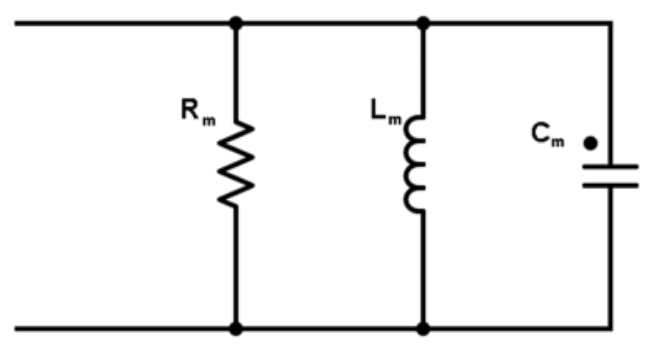

Figure 6: Equivalent circuit model for UWB unit cell

\section{Results and Discussion}

The fabricated design is shown in Fig. $7 \mathrm{~b}$ while the stacking of layers is shown in Fig. 7a.The antenna and AMC layers could either be erected through pillars, however, that would add to weight, which is undesirable for a compact antenna. Therefore, a foam material was used to sandwich the layers. For UWB range, the ROHACELL HF71 foam was sought suitable; owing to its support for wide band planar radiating surfaces [19]. The antenna, foam and AMC layer would be encapsulated in a fabric shaped like a button for the purpose of aesthetics as shown in Figs. $7 \mathrm{a}$ and $7 \mathrm{~b}$. Since the tissues on human chest are curvilinear in nature, therefore, care was taken to place the structure in such a way that the encapsulated button does not touch the human skin. The fabricated sandwiched structure is shown in Fig. 7 b.

\subsection{Frequency Response}

To get an accurate visualization of antenna's performance, it is measured using Agilent Technologies VNA model no. E6362B. Fig. 8 presents the simulated and measured reflection coefficient results, which appear in good uniformity. The band notch behavior can be observed from 4.9 to $5.7 \mathrm{GHz}$ and 7.1 to $7.7 \mathrm{GHz}$. The minute differences between simulated and measured results may be related to 
slight gap between of antenna, foam and AMC layer, finite size of fabricated FSS and tolerances of materials used.

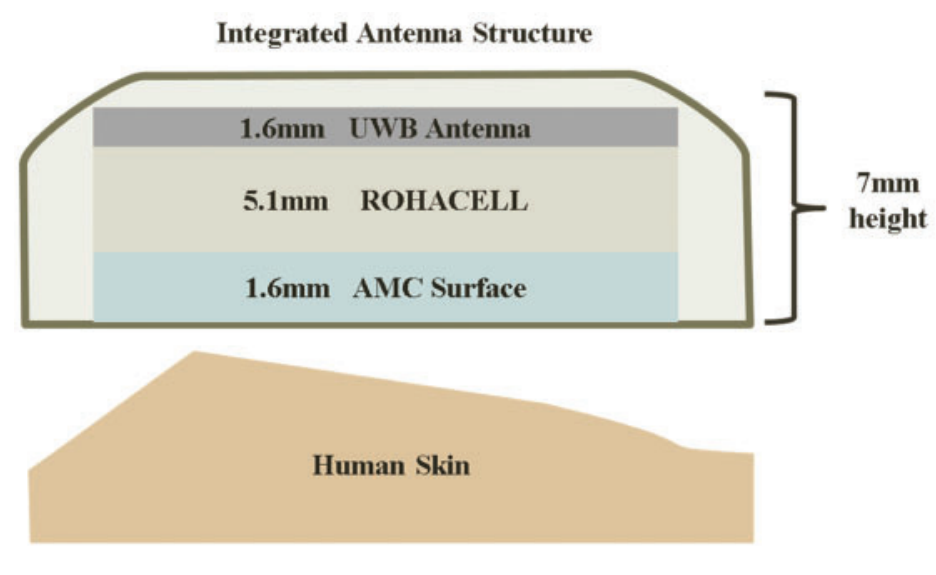

(a)

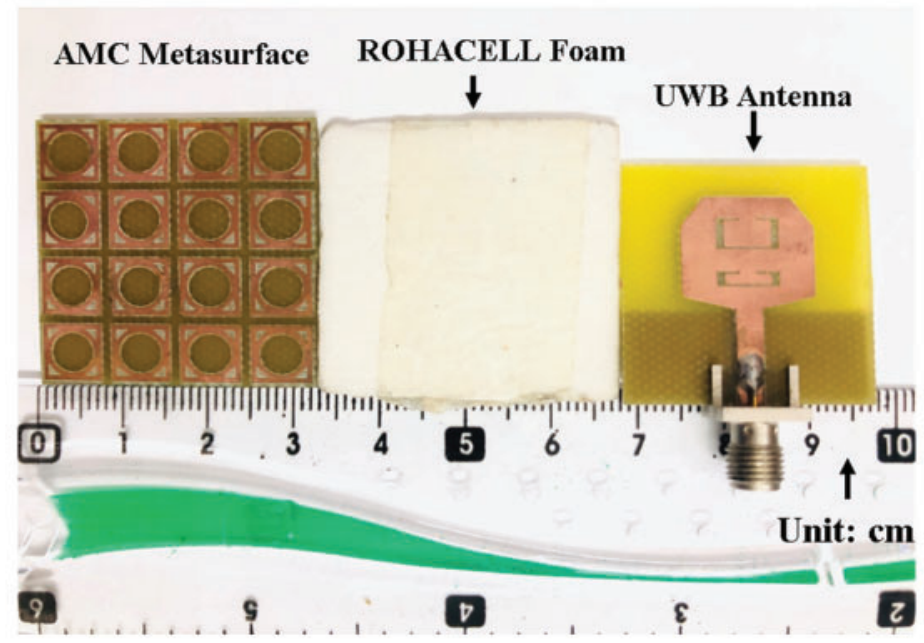

(c)

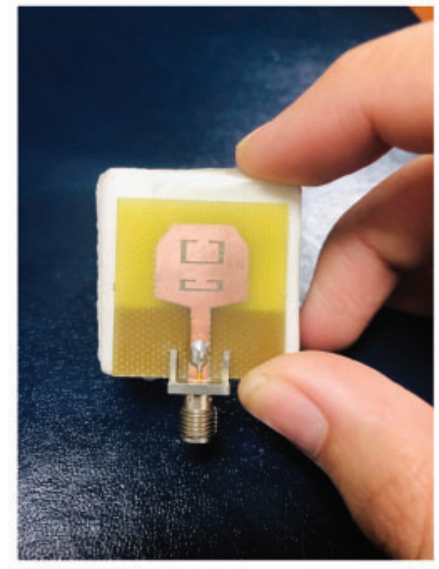

(b)

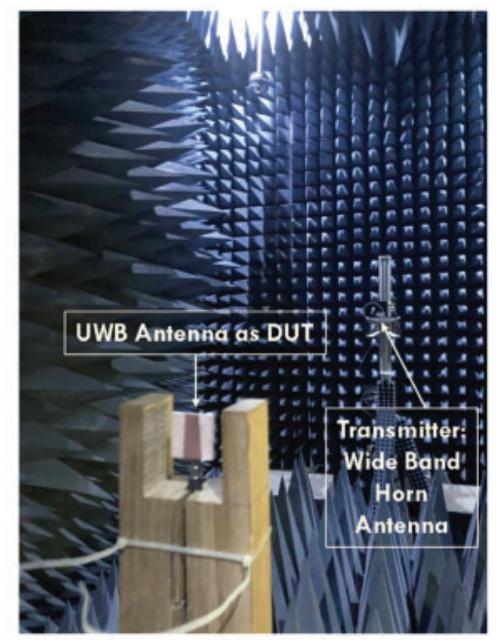

(d)

Figure 7: (a) Layering of antenna, foam and AMC (b) physical representation of structure (c) proposed design with dimensions $(\mathrm{d})$ testing of design in anechoic chamber

\subsection{Radiation Pattern}

The radiation patterns of antenna with and without AMC are shown in Fig. 9, the gain of antenna with AMC is $3.24 \mathrm{~dB}$ while it is $1.2767 \mathrm{~dB}$ without AMC. A significant improvement is seen in the radiation pattern; as it changes from bidirectional to unidirectional front to back ratio, which improves from -0.74 to $9.16 \mathrm{~dB}$. The overall efficiency in terms of gain is $60.6 \%$ and the improvement in Front to Back ratio is $100.8 \%$. The main takeaway in layering the AMC is significant reduction of back lobe which is crucial for wearable applications. The simulated and measured radiation patterns are shown in Fig. 10. The structure was placed in an anechoic chamber as device under test (DUT) with horn antenna as transmitter as shown in Fig. 7 d. The gain patterns are analyzed at 5.08, 5.73, 6.77 and 
7.63 GHz. The radiation patterns are nearly unidirectional at the desired frequency bands, except 7.63 GHz Fig. 10d where the notch occurs. This confirms the validity of the design. The minor dissimilarities can be attributed to fabrication tolerances. The peak gain of $3.24 \mathrm{~dB}$ is achieved at 6.77 GHz Fig. 10c. Whereas the gains at 5.08 and $5.73 \mathrm{GHz}$ are $2.373 \mathrm{~dB}$ (Fig. 10a) and -0.6299 $\mathrm{dB}$ (Fig. 10b) respectively, on account of rising graph at $5.08 \mathrm{GHz}$ and band notch at $5.73 \mathrm{GHz}$ (see Fig. 8).

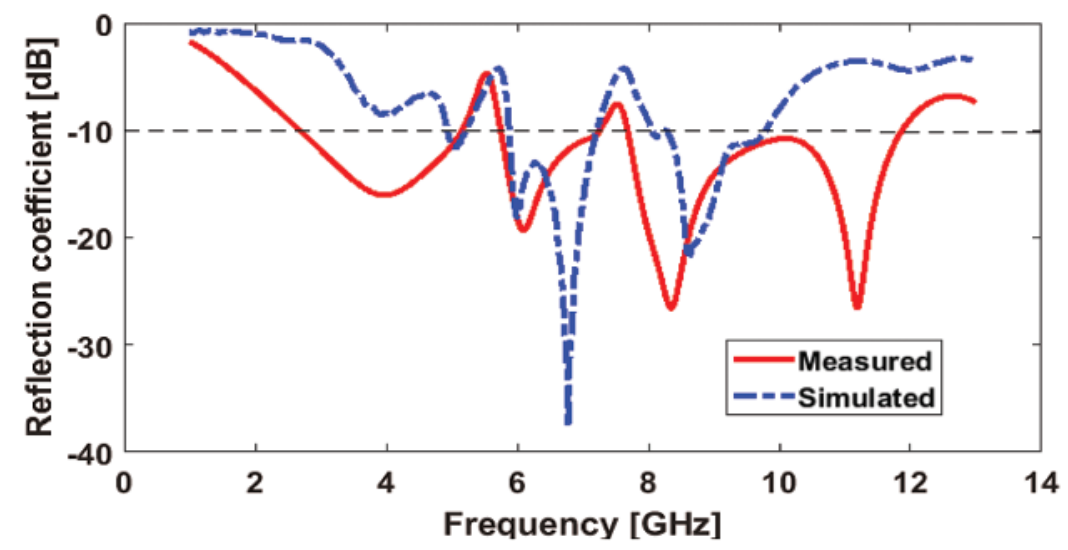

Figure 8: Reflection coefficient response

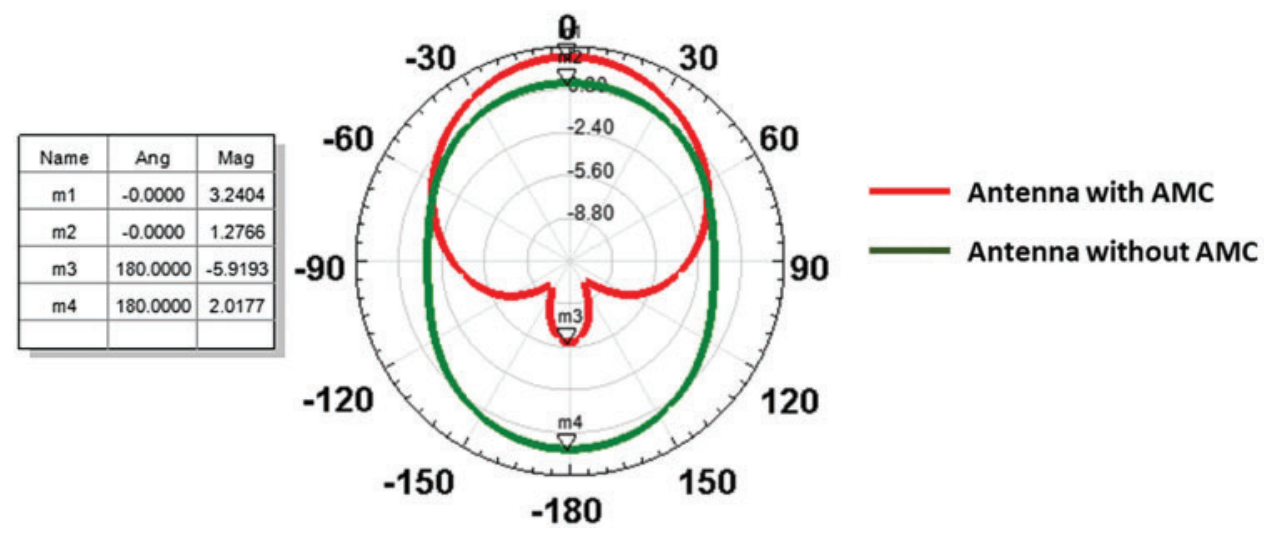

Figure 9: Radiation pattern and gain comparison of antenna with AMC and without AMC

\subsection{SAR Analysis}

The SAR is defined as the RF energy absorbed by the body from a radiating source. It can be numerically related to input power through the expression:

$S A R=\frac{\sigma|E|^{2}}{\rho}$

where, $\sigma$ is the conductivity of the tissue in $\mathrm{S} / \mathrm{m}, \mathrm{E}$ is the electric field in $\mathrm{V} / \mathrm{m}$, and is $\rho$ the mass density of the tissue under consideration in $\mathrm{kg} / \mathrm{m}$.

The unit of SAR is W/kg, usually measured byaveraging over a small volume of 1 or $10 \mathrm{~g}$ of tissue. 


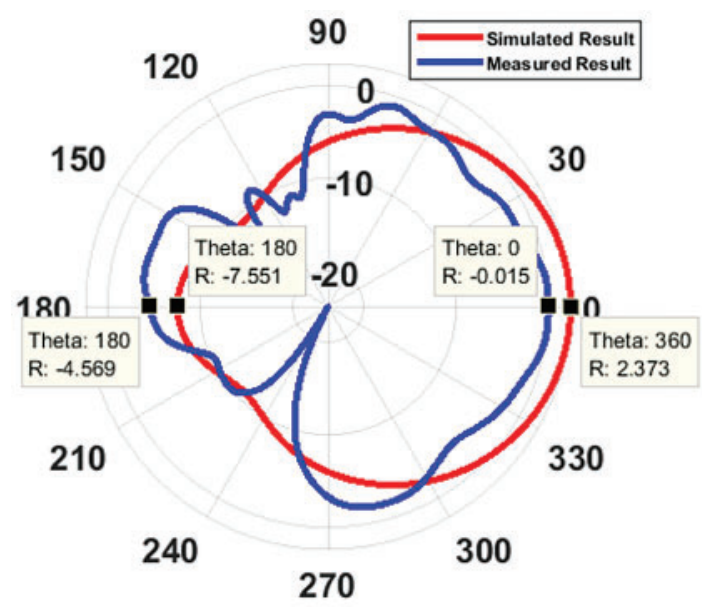

(a)

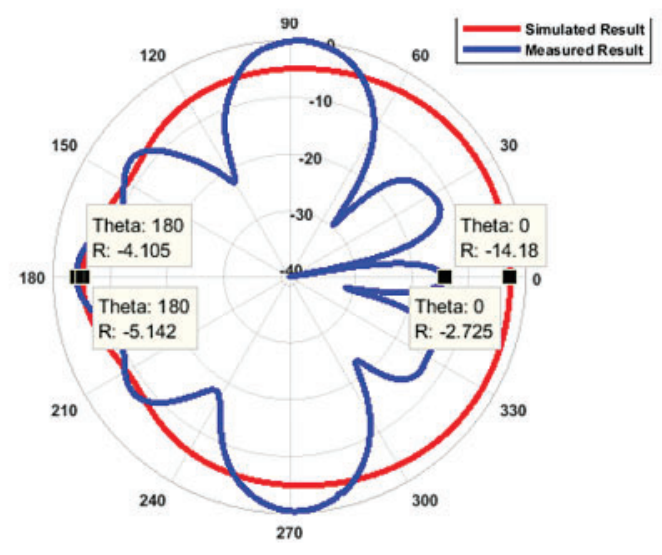

(c)

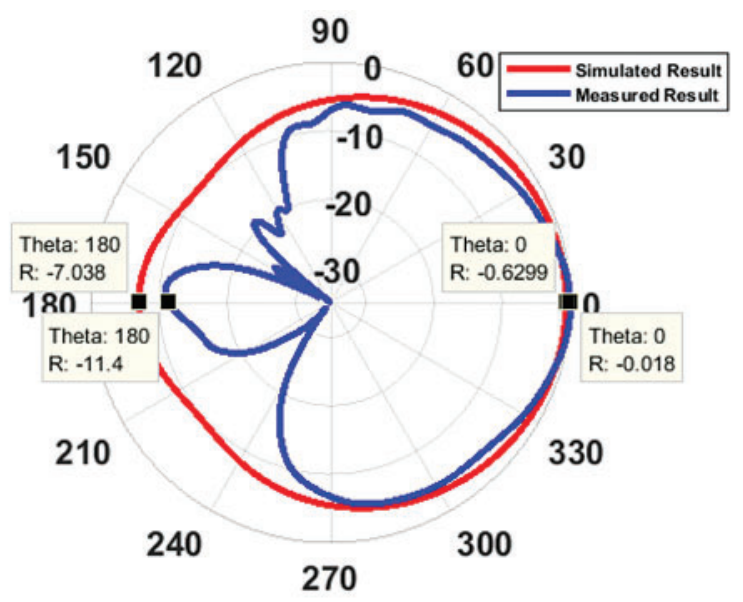

(b)

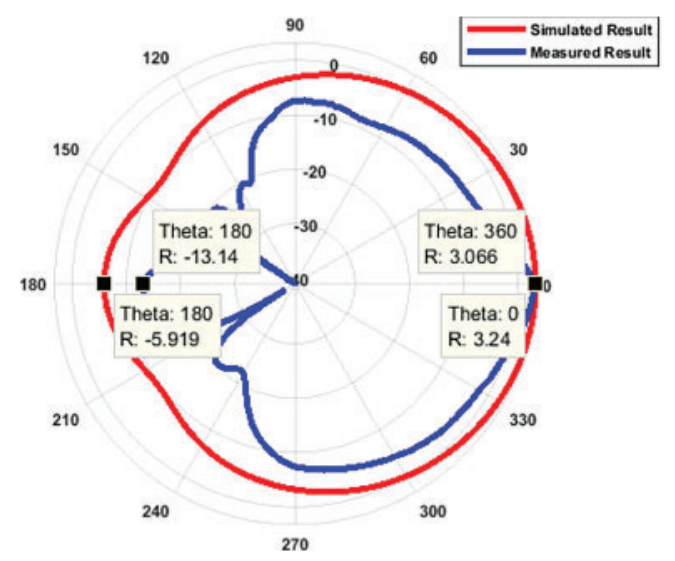

(d)

Figure 10: 2D gain plot of antenna with AMC at (a) $5.08 \mathrm{GHz}$ (b) $5.73 \mathrm{GHz}$ (c) $6.77 \mathrm{GHz}$ (d) 7.63 $\mathrm{GHz}$

To reduce the SAR effects and avoid bending issues, intelligent textile design approaches are used in literature where antennas were placed inside buttons, broaches etc. [20]. The use of AMC in the button antenna can help achieve better bandwidth as well as rigidity to avoid bending effects.

The SAR analysis requires a human body model for EM simulations. With continual improvement in medical imaging and computer graphics, more accurate numerical human body models are proposed [21]. In this work the human body voxel model "Gustav" was used to conduct SAR simulations in CST Microwave Studio. As shown in Fig. 11a, the structure is placed on the chest of the model and SAR values are calculated. During SAR analysis, the device was simulated at its highest certified power level at the mid frequency of UWB band, i.e., $6.5 \mathrm{GHz}$. For the designed structure, the maximum simulated SAR over the body is $0.083 \mathrm{~W} / \mathrm{kg}$, as shown in Fig. 11b, which is well below the SAR limit imposed by FCC i.e., $1.6 \mathrm{~W} / \mathrm{kg}$ averaged over $1 \mathrm{~g}$ under consideration of tissue [22].

It is also observed that using the AMC, the SAR values are significantly reduced. The Fig. 11 shows antenna's impression on human body model and SAR calculations with and without AMC 
metasurface. As seen in Fig. 11 a the SAR value without AMC comes out as $0.566 \mathrm{~W} / \mathrm{kg}$ averaged over $1 \mathrm{~g}$ of tissue and in Fig. $11 \mathrm{~b}$ the SAR value with AMC is $0.083 \mathrm{~W} / \mathrm{kg}$ over $1 \mathrm{~g}$. The percentage difference between SAR of antenna with layered AMC and without AMC is $85.33 \%$.

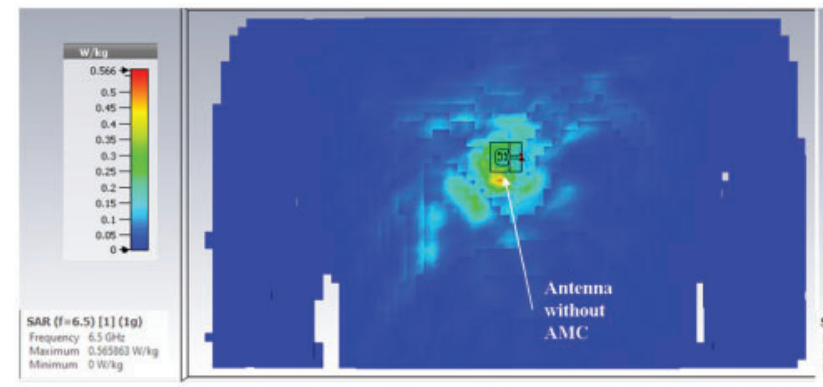

(a)

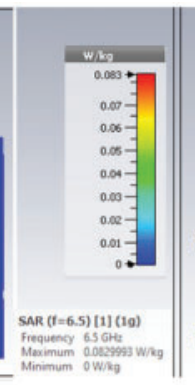

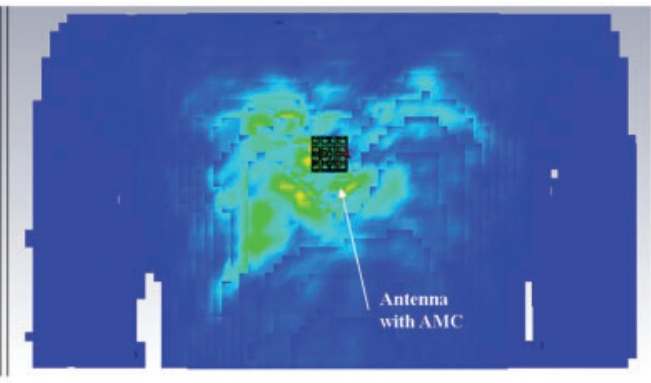

(b)

Figure 11: SAR analysis of UWB structure (a) without AMC and (b) with AMC on human body model "Gustav" in CST

\section{Comparison with State of the Art}

In recent years, various antennas have been presented for UWB applications. A comparison of the state-of-the-art literature is given in Tab. 2. It can be observed that either the antenna doesn't cover the complete range of UWB band, has a large size, omni-directional pattern or a lesser gain. For example, in $[23,24]$, the presented structures are quite compact, however, neither offering band rejection nor provide SAR compliance. Similarly, another compact design [25] produces very less gain (i.e., -0.78 $\mathrm{dB}$ ) while adding an unwanted band rejection at $8 \mathrm{GHz}$. The designs in [11,26] provide satisfactory gain with band notches(s), however, they fail to fulfill SAR requirements. The design proposed in [13] fulfills the criteria for evaluation of UWB wearable antennas, however, the antenna fails to cover entire UWB range. The band notches are too narrow to avoid interference properly and the study does not state gain explicitly. The work reported in [27,28] fulfill the SAR requirement, however, don't produce band notches. In short, previous designs either compromised on SAR, comfort level, gain or bandwidth. Therefore, this study's emphasis is on the design of a compact antenna over the entire UWB conforming to the SAR limitations.

Table 2: Comparison of state of the art on UWB antennas

\begin{tabular}{|c|c|c|c|c|c|c|}
\hline$\overline{\text { Ref. }}$ & Bandwidth & Size & Gain & $\begin{array}{l}\text { Band } \\
\text { rejection }\end{array}$ & SAR & $\begin{array}{l}\text { Front to } \\
\text { back ratio }\end{array}$ \\
\hline [26] & $2.45-12 \mathrm{GHz}$ & $\begin{array}{l}31.88 \times 26 \\
\mathrm{~mm}^{2}\end{array}$ & $2 \mathrm{~dB}$ & $\begin{array}{l}3.27-3.57, \\
5.01-5.45, \\
5.55-6.05, \\
7.05-7.45 \\
\text { and } \\
7.83-8.19 \\
\mathrm{GHz}\end{array}$ & NA & NA \\
\hline
\end{tabular}


Table 2: Continued

\begin{tabular}{|c|c|c|c|c|c|c|}
\hline Ref. & Bandwidth & Size & Gain & $\begin{array}{l}\text { Band } \\
\text { rejection }\end{array}$ & SAR & $\begin{array}{l}\text { Front to } \\
\text { back ratio }\end{array}$ \\
\hline [23] & $3.5-7 \mathrm{GHz}$ & $32 \times 27 \mathrm{~mm}^{2}$ & $0.5 \mathrm{~dB}$ & none & NA & $>10 \mathrm{~dB}$ \\
\hline [24] & $3.1-5.1 \mathrm{GHz}$ & $18 \times 18 \mathrm{~mm}^{2}$ & $2.5 \mathrm{~dB}$ & none & NA & \\
\hline [13] & $3.5-7.5 \mathrm{GHz}$ & $\begin{array}{l}25.6 \times 25.6 \\
\mathrm{~mm}^{2}\end{array}$ & NA & $\begin{array}{l}2,3.5,7.45 \\
\mathrm{GHz}\end{array}$ & $0.05 \mathrm{~W} / \mathrm{Kg}$ & NA \\
\hline [25] & $3.1-12 \mathrm{GHz}$ & $\begin{array}{l}9.45 \\
\mathrm{~mm}^{2}\end{array}$ & $-0.78 \mathrm{~dB}$ & $\begin{array}{l}8 \mathrm{GHz} \\
\text { unwanted } \\
\text { band } \\
\text { rejection }\end{array}$ & NA & NA \\
\hline [11] & $\begin{array}{l}2.9-13.7 \\
\mathrm{GHz}\end{array}$ & $\begin{array}{l}18.7 \\
\mathrm{~mm}^{2}\end{array} \times 17.6$ & $4.4 \mathrm{~dB}$ & $5.1-5.9 \mathrm{GHz}$ & NA & NA \\
\hline [27] & $\begin{array}{l}4.5 \text { to } 13 \\
\mathrm{GHz}\end{array}$ & $\begin{array}{l}100 \times 100 \\
\mathrm{~mm}^{2}\end{array}$ & $6 \mathrm{~dB}$ & none & $0.067 \mathrm{~W} / \mathrm{kg}$ & NA \\
\hline [28] & $\begin{array}{l}\text { Varies with } \\
\text { bending }\end{array}$ & $40 \times 70 \mathrm{~mm}^{2}$ & $7.59 \mathrm{~dB}$ & none & $0.75 \mathrm{~W} / \mathrm{kg}$ & NA \\
\hline This work & $2.9-12 \mathrm{GHz}$ & $\begin{array}{l}33 \times 33 \times \\
6.75 \mathrm{~mm}^{3}\end{array}$ & $3.24 \mathrm{~dB}$ & $\begin{array}{l}5.50-5.67 \\
\text { and } \\
7.16-7.74 \\
\mathrm{GHz}\end{array}$ & $0.083 \mathrm{~W} / \mathrm{kg}$ & $9.159 \mathrm{~dB}$ \\
\hline
\end{tabular}

\section{Conclusion}

In this paper, an AMC backed body worn UWB antenna, having multiple band notches, as a central node of WBAN system targeting low SAR was designed, simulated and fabricated. The antenna is fairly compact having a total size of $33 \times 33 \times 6.75 \mathrm{~mm}^{3}$. To minimize the detuning effects from the human body, the module is backed with AMC that additionally provides shielding to the body, minimizing SAR, maintaining good impedance matching and maximizing antenna effectiveness. The choice of an AMC over PEC provides benefit in terms of substrate thickness which is 3 times less for AMC as compared to the PEC. The antenna's efficiency and SAR value improved by $75.38 \%$ and $85.33 \%$, respectively when the AMC metasurface is placed below it. The measured radiation pattern showed that the fabricated antenna has a good coverage away from the body and minimal radiation towards the body with a $3 \mathrm{~dB}$ beamwidth of 88 degrees. The simple design, miniaturized profile, low SAR and wide operating bands with multiple band notches outperforms other state of the art UWB patch antennas. The study fulfills the requirements of efficiency, compactness, unidirectional pattern and FCC SAR regulations. As the future of wearables is advancing towards sophisticated $\mathrm{mm}$ wave bands and 5G-centric applications, a distinct model for wave propagation, system architecture and fabrication processes is required. The current manufacturing and fabrication methods can also be improved for wearable antennas to avoid deterioration in performance during production. The antenna can be translated into a flexible substrate and more precise fabrication techniques can be used such as conductive graphene, laser cutting, inkjet printing transition metallic niobium diselenide (NbSe2) and MXene ink. 
Funding Statement: This work was supported in part by Engineering and Physical Sciences Research Council grant EP/R511705/1.

Conflicts of Interest: The authors declare that they have no conflicts of interest to report regarding the present study.

\section{References}

[1] G. Breed, "A summary of FCC rules for ultra-wideband communications specific rules by application," High Frequency Electronics, Summit Technical Media, vol. 4, pp. 42-44, 2005.

[2] D. Ferreira, P. Pires, R. Rodrigues and R. F. S. Caldeirinha, "Wearable textile antennas: Examining the effect of bending on their performance," IEEE Antennas and Propagation Magazine, vol. 59, no. 3, pp. 54-59, 2017.

[3] X. Tian, P. M. Lee, Y. J. Tan, T. L. Y. Wu, H. Yao et al., "Wireless body sensor networks based on metamaterial textiles," Nature Electronics, vol. 2, pp. 243-251, 2019.

[4] A. J. A. Al-gburi, I. M. Ibrahim, M. Y. Zeain and Z. Zakaria, "Compact size and high gain of CPW-fed UWB strawberry artistic shaped printed monopole antennas using FSS single layer reflector," IEEE Access, vol. 8, no. 5, pp. 92697-92707, 2020.

[5] A. Y. I. Ashyap, Z. Z. Abidin, S. H. Dahlan, H. A. Majid, M. R. Kamarudin et al., "Highly efficient wearable CPW antenna enabled by EBG-fSS structure for medical body area network applications," IEEE Access, vol. 6, pp. 77529-77541, 2018.

[6] H. R. Raad, A. I. Abbosh, H. M. Al-Rizzo and D. G. Rucker, "Flexible and compact AMC based antenna for telemedicine applications," IEEE Transactions on Antennas and Propagation, vol. 61, no. 2, pp. 524-531, 2013.

[7] D. A. Sehrai, F. Muhammad, S. H. Kiani, Z. H. Abbas, M. Tufail et al., "Gain-enhanced metamaterialbased antenna for $5 \mathrm{G}$ communication standards," Computers, Materials \& Continua, vol. 64, no. 3, pp. $1587-1599,2020$.

[8] K. Agarwal, Y. Guo and B. Salam, "Wearable AMC backed near end-fire antenna for on-body communications on latex substrate," IEEE Transactions on Components, Packaging and Manufacturing Technology, vol. 6.3, pp. 346-358, 2016.

[9] K. Shambavi and Z. C. Alex, "Printed dipole antenna with band rejection characteristics for UWB applications," IEEE Antennas and Wireless Propagation Letters, vol. 9, pp. 1029-1032, 2010.

[10] B. S. Yildiri, B. A. Cetiner, G. Roqueta and L. Jofre, "Integrated bluetooth and UWB antenna," IEEE Antennas and Wireless Propagation Letters, vol. 8, pp. 149-152, 2009.

[11] A. Syed and R. W. Aldhaheri, "A very compact and low profile UWB planar antenna with WLAN band rejection," The Scientific World Journal, vol. 2016, pp. 7, 2016.

[12] T. Xia, S. Yang and Z. Nie, "Band-notched UWB planar antenna with parasitic spiral strips," Microwave and Optical Technology Letters, vol. 53.7, pp. 1532-1535, 2011.

[13] M. Y. ElSalamouny and R. M. Shubair, "Novel design of compact low-profile multi-band microstrip antennas for medical applications," in 2015 Loughborough Antennas \& Propagation Conf. (LAPC), Loughborough, UK, pp. 1-4, 2015.

[14] S. Doddipalli and A. Kothari, "Compact UWB antenna with integrated triple notch bands for WBAN applications," IEEE Access, vol. 7, pp. 183-190, 2019.

[15] H. Pues and A. V. D. Capelle, "Accurate transmission-line model for the rectangular microstrip antenna," IEE Proceedings H: Microwaves Optics and Antennas, vol. 131, no. 6, pp. 334-340, 1984.

[16] N. A. Jan, S. H. Kiani, F. Muhammad, D. A. Sehrai, A. Iqbal et al., "V-shaped monopole antenna with chichena itzia inspired defected ground structure for UWB applications," Computers, Materials and Continua, vol. 65, no. 1, pp. 19-32, 2020.

[17] N. Engheta and R. W. Ziolkowski, "Metamaterials: Physics and engineering explorations," John Wiley and Sons, vol. 1, pp. 1-414, 2006. 
[18] Z. Anatol I. "Handbook of filter synthesis," John Wiley \& Sons, vol. 1, pp. 1-592, 2005.

[19] F. Zhu, S. Gao, A. T. S. Ho, R. A. Abd-Alhameed, C. H. See et al., "Ultra-wideband dual-polarized patch antenna with four capacitively coupled feeds," IEEE Transactions on Antennas and Propagation, vol. 62, no. 5, pp. 2440-2449, 2014.

[20] R. Sreelakshmy and G. Vairavel, "Novel cuff button antenna for dual-band applications," ICT Express, vol. 5 , no. 1 , pp. 26-30, 2019.

[21] T. Nagaoka and S. Watanabe, "Development of voxel models adjusted to ICRP reference children and their whole-body averaged SARS for whole-body exposure to electromagnetic fields from $10 \mathrm{MHz}$ to $6 \mathrm{GHz}$," IEEE Access, vol. 7, pp. 135909-135916, 2019.

[22] K. Guido and A. Kiourti, "Wireless wearables and implants: A dosimetry review," Bio Electromagnetics, vol. 41, no. 1, pp. 3-20, 2020.

[23] M. Klemm, I. Z. Kovcs, G. F. Pedersen and G. Troster, "Novel small-size directional antenna for UWB WBAN/WPAN applications," IEEE Transactions on Antennas and Propagation, vol. 53, no. 12, pp. 3884 3896, 2005.

[24] K. Y. Yazdandoost and K. Hamaguchi, "Very small UWB antenna for WBAN applications," 2011 5th International Symp. on Medical Information and Communication Technology, Montreux, Switzerland, pp. 70-73, 2011.

[25] A. Bekasiewicz and S. Koziel, "Compact UWB monopole antenna for internet of things applications," Electronics Letters, vol. 52, no. 7, pp. 492-494, 2016.

[26] J. Xu, D. Shen, X. Zhang and K. Wu, "A compact disc ultra-wideband (UWB) antenna with quintuple band rejections," IEEE Antennas and Wireless Propagation Letters, vol. 11, pp. 1517-1520, 2012.

[27] H. Yalduz, T. E. Tabaru, V. T. Kilic and M. Turkmen, "Design and analysis of low profile and low SAR fulltextile UWB wearable antenna with metamaterial for WBAN applications," AEU-International Journal of Electronics and Communications, vol. 126, no. 153465, pp. 1-12, 2020.

[28] J. Shailesh, G. Srivastava and R. Purwar, "Bending and SAR analysis on UWB wearable MIMO antenna for on-arm WBAN applications," Frequenz, vol. 75, no. 5-6, pp. 177-189, 2021. 